\title{
Using the Modern Software for Life Cycle Assessment in the Preparation of an Engineer in Automation and Computer-Integrated Technologies
}

\author{
Iryna Dzhygyrey
}

Department of Cybernetics of Chemical Technology Processes, Igor Sikorsky Kyiv Polytechnic Institute, UKRAINE, Kyiv, Peremogy av.37, E-mail: lab.mes@kpi.ua

\begin{abstract}
A new course "Engineering for Sustainable Development» is introduced for bachelors of specialization "Computer-Integrated Technologies of Sustainable Chemical Productions» by the Department of Cybernetics of CTP. One-third of the discipline is addressed life cycle assessment issue, the practical part of which is implemented through the use of SimaPro software.
\end{abstract}

Keywords - automation and computer-integrated technologies, bachelor study, engineer, life cycle assessment, SimaPro, sustainability

\section{Introduction}

The Department of Cybernetics of Chemical Technology Processes of the National Technical University of Ukraine «Igor Sikorsky Kyiv Polytechnic Institute» prepares specialists in the direction of «Automation and Computer-Integrated Technologies» (specialization «Computer-Integrated Technologies of Sustainable Chemical Productions»). Gaining knowledge and creating skills that can be implemented in the field of environmental safety, green growth, and low carbon development by future engineers in the automation of sustainable chemical productions requires the introduction of new educational developments.

\section{«Engineering for Sustainable Development» course for ACIT bachelors}

Educating students of engineering direction in sustainability is very important as for future challenges' solvers [1]. Igor Sikorsky KPI actively implements principles and approaches of education for sustainable development within the framework of the target integrated program "Sustainable Development". In particular, it is a scientific and professional master degree programs with specializations in sustainability, university-wide disciplines on sustainable development («Sustainable Innovative Development», «Basics of Engineering and Technology for Sustainable Development», «Inclusive Green Growth», and «Foundations of Sustainable Development», last one is delivered in English), programs for the professional qualification improvement of scientific and pedagogical staff of universities, etc.

So, among others, 4.5 credits course «Engineering of Sustainable Development» was started for bachelors of the third year of study of the specialization «Computer-Integrated Technologies of Sustainable Chemical Productions») a few years ago. This discipline joins the issues of green chemistry, resource-efficient and cleaner production, and life cycle assessment of product systems. Reading requires professors to continually update and refine materials of the course, use of active forms of learning. The last component of the course introduces students to principles of circular economy, life cycle thinking and its implementation through the creation of life cycle management system on production, but first of all, with the role of life cycle assessment in the development of green economy.

\section{Life Cycle Assessment topic and SimaPro software}

Life cycle assessment of product systems is presented taking into account relevant editions of international environmental standards ISO (subfamily 1404X). When considering this topic, students are acquainted with key concepts and methods of life cycle assessment, phases and stages of the procedure, and peculiarities of working with databases. 
Part of workshops of the course «Engineering of Sustainable Development», in particular on the topic of life cycle assessment, is performed in SimaPro version 9.0. This PRé Sustainability software is a leader among life cycle assessment applications and allows to transparently model and analyze life cycle of product systems, evaluate the environmental impact of a product at all stages of life cycle, identify hot spots in each link of a supply chain. The SimaPro software distinguishes among other life cycle assessment packages by

- $\quad$ the graphical representation of the product life cycle model,

- $\quad$ review of substances unconsidered in assessment and the data of all projects created,

- $\quad$ setting up user-defined parameters for calculations and waste scenarios [2].

SimaPro uses more than ten inventory databases in the calculations, including ELCD of the Joint Research Center of the European Commission and the ecoinvent LCI of the ecoinvent Association, and nearly thirty methods for life cycle assessment on the user's choice, among which such commonly used as Ecological scarcity, ReCiPe, and ILCD.

The use of SimaPro software for performing by students a number of analytical and accounting tasks in the cycle of computer workshops allows them to

- $\quad$ acquire skills to assess and analyze the impact of environmental aspects of the product,

- $\quad$ offer improvements of product system on the basis of life cycle assessment,

- $\quad$ gain experience in identifying the aspects of products characterized by low environmental sustainability, in using life cycle thinking for the development of new and improvement of existing products.

The practical part of the «Life Cycle Assessment» component has been developed in line with recommendations of the software's developers [3] and up-to-date works of leading scientists, researchers and practitioners in life cycle assessment, e.g. [4].

\section{Conclusion}

The life cycle thinking implemented through life cycle management methods and instruments is one of the keystones for engineering education in sustainability. Understanding the role of eco-design and provision of practical skills in life cycle assessment are powerful drivers of change for the chemical industry and beyond.

\section{Acknowledgments}

We would like to thank Dr. Fredy Dinkel (Carbotech AG, Basel | FHNW, Muttenz) for inspiration and PRé Consultants team (Amersfoort) for the opportunity to work with life cycle assessment software package SimaPro.

\section{References}

[1] S. I. Olsen, P. Fantke, A. Laurent, M. Birkved, N. Bey, and M. Z. Hauschild, Sustainability and LCA in engineering education - A course curriculum, In Proc. 25th CIRP Life Cycle Engineering (LCE) Conference, 2018, pp. 627-632.

[2] E. Brilhuis-Meijer, Five Crucial LCA Features in SimaPro. Netherlands: Pré, 2015. [Online]. Available: Pré Consultants, https://www.pre-sustainability.com/news/fivecrucial-lca-features-in-simapro. [Accessed July 15, 2018].

[3] M. Goedkoop, M. Oele, M. Vieira, J. Leijting, T. Ponsioen, and E. Meijer, SimaPro Tutorial. Netherlands: Pré, 2016. [Online]. Available: Pré Consultants, https://www.presustainability.com/download/SimaPro8Tutorial.pdf. [Accessed Jan. 15, 2019].

[4] M. Z. Hauschild, R. K. Rosenbaum and S. I. Olsen, Eds., Life Cycle Assessment: Theory and Practice, Dordrecht, NL: Springer Netherlands, 2018. 